\title{
Psychosocial Determinants of Physical Activity in Undergraduate College Students
}

\author{
Alex B. Shafer ${ }^{*}$, Amy D. Rickman², Fredric L. Goss ${ }^{3}$, Elizabeth F. Nagle ${ }^{3}$ \\ ${ }^{1}$ Department of Health and Human Performance, Montana State University Billings, Billings, MT, USA \\ ${ }^{2}$ Exercise and Rehabilitative Science Department, Slippery Rock University, Slippery Rock, PA, USA \\ ${ }^{3}$ Department of Health and Physical Activity, University of Pittsburgh, Pittsburgh, PA, USA
}

\begin{abstract}
Article Details
Article Type: Research Article

Received date: $16^{\text {th }}$ October, 2017

Accepted date: $06^{\text {th }}$ December, 2017

Published date: $18^{\text {th }}$ December, 2017

*Corresponding Author: Alex B. Shafer, Department of Health and Human Performance, Montana State University Billings, Billings, MT, USA. E-mail: alex.shafer@msubillings.edu

Citation: Shafer AB, Rickman AD, Goss FL, Nagle EF (2017) Psychosocial Determinants of Physical Activity in Undergraduate College Students. J Pub Health Issue Pract 1: 104. https://doi.org/10.33790/jphip1100104.

Copyright: (C2017, This is an open-access article distributed under the terms of the Creative Commons Attribution License 4.0, which permits unrestricted use, distribution, and reproduction in any medium, provided the original author and source are credited.
\end{abstract}

\begin{abstract}
Less than $50 \%$ of adults aged $18-30$ years report meeting the current guidelines for physical activity (PA), with the steepest declines occurring in young adulthood. Theory-based psychosocial factors have been proposed to identify possible modifiable psychological barriers to PA.

Purpose: To explore the relation between PA and key psychosocial determinants: 1) motivation (MO); 2) self-ef- ficacy (SE); 3) social support (SS); 4) exercise enjoyment (EE); and 5) body image (BI) in young adult college students. A secondary aim was to examine whether young adult females and males differ in psychosocial determinants of PA
\end{abstract}

Methods: A cross-sectional correlational design was employed.

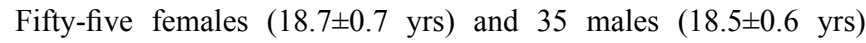
participated. Weekly minutes of hard PA, very hard PA, and total weekly minutes of PA (7-Day PA Recall) served as the dependent variables. Determinant variables were assessed using standardized question- naires.

Results: For females, SE, EE, MO, SS from friends, and BI were correlated $(\mathrm{p}<0.05)$ to total weekly minutes of PA. The combination of EE, MO, SS, and BI explained nearly $43 \%$ of the variance in total weekly minutes of PA ( $22=0.426, F(4,50)=9.294, p<0.001)$. For males, EE was correlated $(\mathrm{p}<0.05)$ to minutes of hard PA, minutes of very hard PA, and total weekly minutes of PA. A stepwise multiple regression analysis resulted in EE being the only determinant selected for the model $(\mathrm{R} 2=0.174, \mathrm{~F}(1,33)=6.949, \mathrm{p}=0.013)$.

Conclusion: EE was a significant psychosocial determinant of PA among young adult male and female college students. Other psychosocial determinants of PA in females include MO, SS, and BI. These psychosocial variables deserve consideration when designing future behavioral interventions to increase PA in young adult college students.

Keywords: Physical activity; Psychosocial determinants; College students

\section{Introduction}

Considered a major public health concern, physical inactivity (PIA) and increased body fatness are linked to metabolic risk factors and chronic disease in both men and women [1,2]. Although most evidence examining this issue has predominantly focused on the general adult population age 18 to 64 years, younger adults are also affected. Specifically, young adults transitioning from high school to college have consistently shown to partake in lower levels of physical activity (PA) and exhibit high rates of overweight/ obesity, undesirable total cholesterol, high blood pressure, and other coronary heart disease risk factors [3-5]. Despite these negative health indicators, young adults are an often-understudied population, compared to children/adolescents, middle-aged/ older adults, and other special populations. Young adults appear in fewer investigations exploring determinants or factors that influence PA behavior, in addition to fewer behavioral interventions specifically targeting PIA and overweight/obese young adults [6-8]. The benefits of studying this population who are transitioning to adulthood are significant considering PA participation, as a young adult (18 years) has been shown to influence PA participation later in life $[9,10]$. Specifically, interventions targeted towards college freshman may provide a platform to reach a relatively accessible population that is at great risk of becoming less active because of the lifestyle changes experienced during the transition from high school to college.

Despite the strong evidence supporting the importance of PA for healthy living, there remains a trend of sedentary behavior within the U.S. population. It is reported that only $39.9 \%$ of females and $50.4 \%$ of males aged 18-30 years report meeting the recommended guidelines for regular PA [14]. While a pattern of consistent, sharp declines in PA among young adults between the ages of 18-24 years has been observed, it appears the factors associated with a spontaneous change or decrease in PA across the lifespan are multifaceted and complex [11-13]. Therefore, it is important to study young adults within a targeted college population so that in the future, specific behavioral interventions can be designed to maintain or even increase current PA levels. This may then help to prevent or delay sedentary behavior in later adulthood.

An important step to developing effective health promotion programs and behavioral interventions designed to increase PA is to first understand the determinants of behavior for the target population. 
Factors that influence participation include demographic, social, and environmental characteristics. In addition, it is felt that various psychological determinants drive exercise behavior [15-17]. Previous investigations [18-19] have used a com- bination of the Transtheoretical Model of Behavior Change [17], Social Cognitive Theory [15] and the Self-De- termination Theory [16] to examine why individuals might be resistant to PA behavior change. Investigations have shown varying PA patterns between specific age groups and sex groups [20-21]. However, to date there is insufficient data on the young adult population to be able to completely understand these PA patterns.

Five modifiable determinants of PA demonstrated as having particularly strong relationships to PA in adults include: 1) selfefficacy; 2) social support; 3) motivation; 4) enjoyment; and 5) body image [22-26]. Few studies have explained the relationship of these variables to PA behavior in young adult college students. Previous studies have shown that age and gender appear to influence modifiable determinants in adults 18-64 years [20]. De Bourdeaudhuij et al., (2002) demonstrated social support to be a stronger predictor of PA in females, while motivation and an opportunity for competition was a stronger predictor in males. Additionally, health concerns have been reported as a significant barrier to PA in older adults but not younger adults [20]. This information demonstrates that psychosocial determinants of PA may differ between subgroups. However, this age range (18- 64 years) is too broad to generalize specifically to young adult college students and the identification of age and gender specific determinants of PA have not been thoroughly examined in this population [20].

Understanding the factors that influence decisions associated with PA, may improve how instruction, coaching, or interventions are designed. This in turn may increase affect, enjoyment, participation, and adherence in PA, thus improving the overall health of young adults. It is anticipated that once identified, the determinants of PA may become target variables in freshman orientations or interventions aimed at improving PA behaviors among undergraduate college students. Understanding such factors could assist in the design, implementation, and promotion of PA recommendations and assist young adults transitioning into life after high school. This may lead to improved attendance, participation, and increased compliance to PA programs, as well as contribute to the adoption of healthy lifestyle behaviors that enhance health outcomes in young adults.

The primary aim of this investigation was to examine the relation between self-reported PA and the following modifiable psychosocial variables: 1) self-efficacy; 2) social support; 3) motivation; 4) exercise enjoyment; and 5) body image in a sample of young adult female and male college students. The secondary aim of this investigation was to examine whether young adult female and male college students differ in psychosocial predictors of PA behavior.

\section{Methods}

\section{Research Design}

This investigation employed a cross-sectional correlational design. Total weekly minutes of PA served as the dependent variable. The predictor variables were assessed using standardized questionnaires in a counterbalanced fashion and included the following measures: 1) self-efficacy; 2) social support; 3) motivation; 4) enjoyment; and 5) body image. All investigational procedures were approved by the university's Institutional Review Board (IRB).

\section{Participants}

Fifty-five females and thirty-five males, ages 18-20 years were recruited from a large urban university campus via flyers and word of mouth. The mean age was $18.7 \pm 0.7$ years for the combined sample. Seventy-eight per- cent of females and $97 \%$ of the males enrolled in this investigation were college freshmen. The distribution of race reflected the university's student body with $67.8 \%$ of the total sample described as White/Caucasian. Sub- jects were excluded from participation if they: 1) had an orthopedic, cardiovascular and/or metabolic condition that would limit participation in PA; 2) possessed implanted devices (such as a cardiac defibrillator); 3 ) were pregnant; and/or 4) participated in collegiate (NCAA) athletics.

Descriptive characteristics including: 1) age; 2) gender; 3) race/ ethnicity; and 4) anthropometrics were as- sessed for demographic purposes by a questionnaire (Table 1 ).

\begin{tabular}{|l|l|l|l|}
\hline Characteristics & Male $(\mathrm{n}=35)$ & Female $(\mathrm{n}=55)$ & Total $(\mathrm{n}=90)$ \\
\hline Demographic & & & \\
\hline Age (yrs) & $18.5 \pm 0.6$ & $18.7 \pm 0.7$ & $18.7 \pm 0.7$ \\
\hline Freshmen (\%) & 97.1 & 78.2 & 85.6 \\
\hline Race/ethnicity & & & \\
\hline White (\%) & 62.9 & 70.9 & 67.8 \\
\hline African American (\%) & 5.7 & 10.9 & 8.9 \\
\hline Hispanic (\%) & 5.7 & 0.0 & 2.2 \\
\hline Asian American (\%) & 25.7 & 7.3 & 14.4 \\
\hline Other (\%) & 0.0 & 10.9 & 6.7 \\
\hline Living on Campus (\%) & 94.3 & 89.1 & 91.1 \\
\hline Employed (\%) & 20.0 & 29.1 & 25.6 \\
\hline Anthropometrics & & & \\
\hline Height (cm) & $175.7 \pm 7.5$ & $163.6 \pm 7.3$ & $168.3 \pm 9.5$ \\
\hline Weight (kg) & $72.8 \pm 10.4$ & $62.6 \pm 8.3$ & $66.6 \pm 10.4$ \\
\hline BMI (kg/m $\left.{ }^{2}\right)$ & $23.3 \pm 3.0$ & $23.4 \pm 2.9$ & $23.3 \pm 2.9$ \\
\hline$\%$ body fat & $13.4 \pm 4.4$ & $26.2 \pm 5.8$ & $21.2 \pm 8.2$ \\
\hline Waist circumference (cm) & $79.8 \pm 7.1$ & $72.4 \pm 11.0$ & $68.5 \pm 7.8$ \\
\hline Systolic Blood Pressure (mmHg) & $117.5 \pm 7.6$ & $109.1 \pm 10.1$ & $112.3 \pm 10.1$ \\
\hline Diastolic Blood Pressure (mmHg) & $71.1 \pm 6.7$ & $66.8 \pm 8.1$ & $68.5 \pm 7.8$ \\
\hline Tabl Partipant Charactics & & \\
\hline
\end{tabular}

Table 1. Participant Characteristics, Values are Means \pm Standard Deviation (SD) or $n(\%)$ 


\section{Procedures}

During the single testing session, written consent to participate was obtained prior to the collection of blood pressure and anthropometric measures. Immediately following the anthropometric measurements, a packet containing questionnaires regarding demographic, psychosocial determinants of PA, and self-report PA was completed. The psychosocial variables assessed were related to five core questions on the following:

1) self-efficacy; 2) social support; 3) motivation; 4) enjoyment; and 5) body image. The five scales ranged from 1 to 20 items in length and consisted of brief question and answer statements.

\section{Assessment of Physical Activity}

The Stanford 7-day Physical Activity Recall Scale (7-D PAR) [27] was used during the PA interview to assess self-reported regular PA (min•wk-1). This instrument has been used in multiple investigations assessing PA patterns in young adults and estimates both workrelated and non-work-related PA. The 7-D PAR has demonstrated adequate test-retest reliability (0.73) [27], and validity compared to direct measures of PA [28]. This instrument allows for a comparison of determinants between various intensities and modes of PA. For each day of the past week, participants reported approximate number of hours and minutes they spent sleeping, participating in moderate, hard, and very hard PA. During the interviewer administered 7-D PAR, subjects were given standardized verbal descriptors for each activity category including moderate, hard, and very hard.

\section{Assessment of Psychosocial Variables}

Exercise self-efficacy was assessed using a scale developed by Marcus et al. (1992) [24]. This instrument assesses confidence in one's ability to exercise under conditions that might affect participation. Internal consistency has been demonstrated to be $r=0.76$ [24]. Scores from this brief 5 -item questionnaire were calculated by computing the mean of all five items for each client. A total score could range from 1 to 5 points, with one representing lowest efficacy to exercise, and five representing the highest (most confident).

Social support for exercise was measured using the Social Support for Exercise Scale and demonstrates concurrent and criterion-related validity $(\mathrm{r}=0.61-0.91)$ to exercise habits [25]. The scale includes two subscales designed to differentiate between friend (peers-5item) and family (member of household-15-item) support for PA. Subjects rated the frequency of support from family and friends on a 5-point Likert scale [1 (none) and 5 (very often)] for each item on the questionnaire. The total sum of all subscales was recorded with a lower score representing less support, and a higher score representing higher support.

Motivation to be physically active was measured using the Situational Motivation Scale (SIMS) [22]. This 16-item scale assess four subscales of motivation that include: 1) Intrinsic motivation; 2) Identified regulation; 3) External regulation; and 4) Amotivation. The questionnaire assesses reasons for participating in exercise on a 7-point Likert scale [1 corresponds not at all to a motivational factor and 7 corresponds exactly to a motivational factor]. Internal consistency has been demonstrated to be $r=0.85$ [22]. A total sum of each subscale was recorded. Subscale 1 represented Intrinsic motivation, while Subscales 2. (Identified regulation) and 3. (External regulation) were combined to represent Extrinsic motivation. Lower scores are associated with less motivation, while higher scores are associated with higher motivation.

Exercise enjoyment was assessed using the Physical Activity Enjoyment Scale (PACES) that determines "the extent to which an individual experiences a particular PA as enjoyable at a given point in time" [23]. Factorial validity and convergent evidence for construct validity indicate that the PACES is a valid measure of PA enjoyment [23]. Subjects rated their feelings about PA on a seven point Likert scale for 18 items. A sum of all items together for a final score ranged from a possible 18 (lowest enjoyment) to 126 (highest enjoyment). Higher scores reflected greater enjoyment.

The Contour Drawing Rating Scale was used to measure Body Image [26]. Seven-day test-retest reliability for self-ideal ratings using the Contour Drawing Rating Scale was moderately strong (0.79) and the scale has been validated against body weight parameters (0.71) [26]. The scale consists of a nine-figure silhouette rating used to measure body perception. Subjects indicated which figure best represents their body shape, as well as the figure that best represents their desired body shape. Each body shape was given a number, which was reported as the body image score.

\section{Data Analysis}

Separate analyses were conducted by sex for males and females, as previous evidence has supported that the relative contribution of predictor variables may differ by gender [20]. Descriptive statistics were computed for demographics, BMI, the five predictor variables, and the dependent variable of PA. Distributions of variables were examined within each gender to identify any instances of outliers and/or evidence of severe violation of the assumption of normality.

Prior to regression analysis, bivariate correlations between all pairs of variables were computed for the male and female subsamples. Finally, separate simultaneous multiple regression analyses were carried out for the male and female samples. Total weekly minutes of PA served as the primary dependent variable. The predictor variables include motivation (intrinsic and extrinsic), self-efficacy, social support (family and friends), enjoyment, and body image. Statistical significance was accepted at an alpha level of $\mathrm{p}<0.05$.

\section{Results}

Ninety apparently healthy college females $(n=55)$ and males $(n=35)$ aged 18 to 20 years were recruited from a large urban university to participate in this investigation. Of this cohort, $86 \%$ were college freshmen. A summary of descriptive characteristics for all subjects is provided in Table 1 . Subjects presented with primarily healthy body weight, BMI, percent body fat, and waist circumference measurements when compared to the American College of Sports Medicine (ACSM)/American Heart Association (AHA) Guidelines [29] for young adults of the same age.

\section{Physical Activity Recall}

Minutes per week spent engaged in moderate, hard, and very hard PA for the seven-day period preceding the day of the investigatoradministered interview was collected. Total minutes of PA per week for each category can be seen in Table 2. The mean total PA was 524 minutes per week and 393 minutes per week for males and females, respectively. These values meet and exceed the current ACSM/AHA recommendations for minutes of PA per week [29]. In addition, $60.0 \%$ of subjects reported greater than 30 minutes of moderate PA five or more days per week, just above the national average of $50.6 \%$ [14]. However, minutes of total PA were lower than values reported by Sallis et al. (1985), for young adult males ( 966.0 mins•wk-1) and females (553.8 mins $\left.{ }^{\bullet} \mathrm{wk}-1\right)$ in the original 7D-PAR validation studies [27,30]. In addition, Salmon et al. (2003), reported nearly identical findings for total minutes of self-report PA (456 \pm 378 mins $\bullet$ wk-1) in young adults aged 18-30 years, compared to the combined sample in this investigation (444.4 \pm 261.5 mins $\bullet$ wk-1) [31].

\section{Psychosocial Determinants}

The assessment of 1) self-efficacy; 2) social support; 3) motivation; 4) exercise enjoyment; and 5) body image was performed using standardized questionnaires via investigator interview. The mean $( \pm \mathrm{SD})$ scores for the male and female sample are presented in Table 3. 


\begin{tabular}{|c|c|c|c|}
\hline & Male $(\mathrm{n}=35)$ & Female $(\mathrm{n}=55)$ & Total $(\mathrm{n}=90)$ \\
\hline Moderate $(\min \bullet w k-1)$ & $171.2 \pm 120.8$ & $193.7 \pm 129.2$ & $184.9 \pm 125.8$ \\
\hline Hard (min•wk-1) & $237.0 \pm 221.4$ & $104.8 \pm 114.5$ & $156.2 \pm 175.7$ \\
\hline Very Hard (min•wk-1) & $116.8 \pm 185.9$ & $94.9 \pm 194.4$ & $103.4 \pm 109.4$ \\
\hline Total (min•wk-1) & $524.0 \pm 271.9$ & $393.3 \pm 243.5$ & $444.5 \pm 261.5$ \\
\hline
\end{tabular}

Table 2. Seven Day-Physical Activity Recall Results

Values are Means \pm Standard Deviations (SD)

\begin{tabular}{|l|l|l|l|}
\hline & Male $(\mathrm{n}=35)$ & Female $(\mathrm{n}=55)$ & Total $(\mathrm{n}=90)$ \\
\hline Self-efficacy & $3.29 \pm 0.64$ & $2.87 \pm 0.61$ & $3.03 \pm 0.65$ \\
\hline Social Support-Family & $28.69 \pm 7.72$ & $33.51 \pm 13.29$ & $31.63 \pm 11.64$ \\
\hline Social Support-Friend & $12.77 \pm 4.50$ & $15.58 \pm 5.32$ & $14.49 \pm 5.18$ \\
\hline Motivation-Intrinsic & $5.71 \pm 0.92$ & $5.15 \pm 1.12$ & $5.37 \pm 1.08$ \\
\hline Motivation-Extrinsic & $8.91 \pm 1.61$ & $9.55 \pm 1.72$ & $9.31 \pm 1.70$ \\
\hline Motivation-Total & $16.16 \pm 2.11$ & $12.27 \pm 2.33$ & $16.23 \pm 2.23$ \\
\hline Exercise Enjoyment & $104.97 \pm 12.78$ & $100.20 \pm 13.44$ & $104.06 \pm 13.32$ \\
\hline Body Image & $0.86 \pm 0.77$ & $1.00 \pm 0.745$ & $0.94 \pm 0.75$ \\
\hline
\end{tabular}

Table 3. Descriptive Statistics for Independent Variables

Values are Means \pm Standard Deviations (SD)

\section{Bivariate Correlations between All Independent and Dependent} Variables

To determine the association between PA and the psychosocial determinants, Pearson Product-Moment correlations are presented in Tables 4 and 5. For females, self-efficacy was significantly correlated to minutes of hard $(r=0.251)$ and total minutes $(r=0.258)$ of PA. Exercise enjoyment was significantly correlated $(p<0.05)$ to moderate $(\mathrm{r}=0.284)$, very hard $(\mathrm{r}=0.257)$, and total minutes $(\mathrm{r}=0.418)$ of PA. Motivation was significantly correlated to minutes of very hard $(\mathrm{r}=0.245)$ and total minutes $(\mathrm{r}=0.379)$ of PA. Social support from friends was significantly correlated to minutes of hard PA ( $\mathrm{r}=-$ 0.237 ), and body image was significantly correlated to minutes of very hard PA ( $r=-0.242)$. There was no association between support from family and PA for females.

\begin{tabular}{|l|l|l|l|l|l|}
\hline & & $\begin{array}{l}\text { Minutes of } \\
\text { Moderate PA }\end{array}$ & $\begin{array}{l}\text { Minutes of } \\
\text { Hard PA }\end{array}$ & $\begin{array}{l}\text { Minutes of } \\
\text { Very Hard PA }\end{array}$ & $\begin{array}{l}\text { Total PA } \\
\text { Minutes }\end{array}$ \\
\hline Self-Efficacy & Pearson Correlation Sig (1-tailed) & .141 & $.251^{*}$ & .082 & $.258^{*}$ \\
& & .152 & .032 & .276 & .029 \\
\hline Enjoyment & Pearson Correlation Sig. (1-tailed) & $.284^{*}$ & .133 & $.257^{*}$ & $.418^{* *}$ \\
& & .018 & .167 & .029 & .001 \\
\hline Motivation & Pearson Correlation Sig. (1-tailed) & .205 & .158 & $.245^{*}$ & $.379^{* *}$ \\
& & .066 & .125 & .035 & .002 \\
\hline Support Friends & Pearson Correlation Sig. (1-tailed) & -.056 & $-.237^{*}$ & .130 & -.037 \\
& & .341 & .041 & .172 & .393 \\
\hline Support Family & Pearson Correlation Sig. (1-tailed) & .090 & -.133 & .136 & .094 \\
& & .257 & .167 & .160 & .248 \\
\hline Body Image & Pearson Correlation Sig. (1-tailed) & .026 & .039 & $-.242^{*}$ & -.161 \\
& & .425 & .389 & .038 & .121 \\
\hline
\end{tabular}

Table 4. Pearson Correlations between Physical Activity and Independent Variables for Females $\mathrm{PA}=$ Physical Activity, $\left({ }^{*} \mathrm{p}<0.05, * * \mathrm{p}<0.01\right)$ 


\begin{tabular}{|l|l|l|l|l|l|}
\hline & & $\begin{array}{l}\text { Minutes of } \\
\text { Moderate PA }\end{array}$ & $\begin{array}{l}\text { Minutes of } \\
\text { Hard PA }\end{array}$ & $\begin{array}{l}\text { Minutes of } \\
\text { Very Hard PA }\end{array}$ & $\begin{array}{l}\text { Total PA } \\
\text { Minutes }\end{array}$ \\
\hline Self-Efficacy & Pearson Correlation Sig (1-tailed) & -.070 & .184 & .150 & .221 \\
& & .345 & .146 & .195 & .101 \\
\hline Enjoyment & Pearson Correlation Sig. (1-tailed) & -.149 & $.315^{*}$ & $.331^{*}$ & $.417^{*}$ \\
& & .197 & .033 & .026 & .006 \\
\hline Motivation & Pearson Correlation Sig. (1-tailed) & .045 & .121 & .104 & .189 \\
& & .398 & .244 & .279 & .139 \\
\hline Support Friends & Pearson Correlation Sig. (1-tailed) & -.244 &. .260 & .074 & .154 \\
& & .079 & .065 & .336 & .188 \\
\hline Support Family & Pearson Correlation Sig. (1-tailed) & -.151 & -.157 & .148 & -.094 \\
& & .193 & .184 & .198 & .296 \\
\hline Body Image & Pearson Correlation Sig. (1-tailed) &.- .162 & -.018 & .121 & -.004 \\
& & .176 & .459 & .244 & .491 \\
\hline
\end{tabular}

Table 5. Pearson Correlations between Physical Activity and Independent Variables for Males

For males, only exercise enjoyment was significantly correlated $(\mathrm{p}<0.05)$ with minutes of hard $(\mathrm{r}=0.315)$, minutes of very hard $(\mathrm{r}=0.331)$, and total minutes $(\mathrm{r}=0.417)$ of PA. There was no significant association between self-efficacy, motivation, social support, or body image with PA.

\section{Regression Analyses}

Separate stepwise multiple regression analyses were performed for the male and female samples. Total weekly minutes of PA served as the dependent variable. The predictor variables include self-efficacy, social support, total motivation, enjoyment, and body image. Social support from family and social support from friends were treated as separate variables. When total minutes of PA were predicted in females, the combination of enjoyment $(\mathrm{p}<0.001)$, extrinsic motivation $(\mathrm{p}<0.001)$, support from friends $(\mathrm{p}=0.004)$, and body image $(\mathrm{p}=0.034)$ explained $43 \%$ of the variance in total minutes of PA ( $R 2=0.426, F(4,50)=9.294, p<0.001)$. In males, only exercise enjoyment explained a significant proportion of variance $(\mathrm{p}=0.013)$. In this model, enjoyment accounted for $17 \%$ of the variance in total minutes of $\mathrm{PA}(\mathrm{R} 2=0.174, \mathrm{~F}(1,33)=6.949, \mathrm{p}=0.013)$.

Results suggest that exercise enjoyment is the only common predictor variable among the female and male samples assessed in this investigation. Additionally, motivation $(\mathrm{R} 2=0.116)$, social support from friends $(\mathrm{R} 2=0.081)$, and body image $(\mathrm{R} 2=0.054)$ also appear to influence total weekly minutes of PA for females. Results from this investigation support the use of constructs derived from theoretical models that include: 1) enjoyment and motivation (Self Determination Theory); and 2) self-efficacy and social support (Social Cognitive Theory), because of their significant association with PA.

Previous studies have shown that most subjects overestimate their PA when using recalls [32]. In the present investigation $94 \%$ of subjects reported walking as a form of PA during the PA recall. This accounted for an average of $129.9 \pm 109.9$ minutes of walking per week and $68 \%$ of total minutes of moderate activity reported. Much of this self-reported walking served as a method of transportation rather than a structured bout of planned PA. This frequent walking might account for the elevated total minutes of PA in this sample. Therefore, an alternative to total minutes of PA was calculated using total minutes of PA, and excluded minutes of recorded walking. With walking removed from the dependent variable, a stepwise regression analysis was conducted for both male and female samples. Enjoyment remained the single significant contributing predictor as the stepwise regression model explained $20 \%$ of the variance $(\mathrm{R} 2=0.197(\mathrm{~N}=35$, $\mathrm{p}=0.110$ ) in total minutes of PA for males. For females, extrinsic motivation became the lone predictor of the stepwise regression model $(\mathrm{R} 2=0.145, \mathrm{~F}(1,53)=8.9, \mathrm{p}=0.004)$, explaining $15 \%$ of the total variance in PA. The regression models from PA excluding walking minutes did not explain significantly more variance than total minutes of PA. These findings suggest that the elevated minutes of moderate activity as a result of walking may not have influenced the primary results of this investigation. This method of calculating PA should be explored further in future studies that explore determinants of PA behaviors.

\section{Discussion}

The primary aim of this investigation was to explore the relation between self-reported PA and modifiable psychosocial variables of: 1) motivation; 2) self-efficacy; 3) social support; 4) exercise enjoyment; and 5) body image in a sample of young adult male and female college students. A secondary aim was to examine whether young adult males and females differed in psychosocial predictors of PA.

Consistent with previous reports in the adult population [19,33] self-efficacy, exercise enjoyment, total motivation, social support from friends, and body image were significantly correlated with PA in the study sample. The 7D-PAR was designed in such a way that moderate, hard, very hard, and total minutes of PA can be examined independently. Based on the Pearson Product-Moment correlations comparing the independent (predictor) variables to the varying levels of PA, exercise enjoyment was the only variable correlated to moderate PA in the female sample. Additionally, self-efficacy and social support from friends were significantly correlated to weekly minutes of hard PA for females, while exercise enjoyment was the only variable significantly correlated to minutes of hard PA in males. Finally, motivation, exercise enjoyment, and body image were significantly correlated to minutes of very hard PA for females, while exercise enjoyment was again the single variable correlated to minutes of very hard PA. These results indicate that some predictor variables may be more important than others, depending on the intensity of PA. However, based on the present findings and sample size of this investigation, differences in correlations between predictor variables and the intensity categories are inconclusive and warrant future exploration. 
Results of the present investigation are similar to those of a longitudinal investigation of 2,726 high school students transitioning into college, where psychosocial factors of self-efficacy, social support, and perceived benefits/barriers significantly predicted leisure time PA [34]. Additionally, Van Dyck et al., (2014) observed decreases in self-efficacy, increases in perceived barriers to PA and significant decreases in leisure time PA between the last semester of high school and the first semester of the sophomore year of college [34]. These changes are representative of challenges health professionals face when attempting to influence PA behaviors in young adults.

\section{Limitations}

This investigation employed a cross-sectional design. This did not allow for causality to be determined among identified determinants and PA behavior. A longitudinal investigation would allow investigators to more effectively track PA patterns and determinants over time. Furthermore, this investigation relied on a self-report PA questionnaire as opposed to more objective measures such as wearable activity monitors or doubly-labeled water. Perceived barriers (lack of interest, external obstacles, lack of time, embarrassment, psychological problems, and health barriers) were not measured in this investigation and may assist with explaining the variance in PA in young adults [19]. The apparently healthy sample population used in this investigation presented with normal blood pressure, body composition, and estimated fitness levels. They were more fit and reported higher PA levels than the national averages [14]. As with most investigations involving volunteer subjects and the topics of health and PA, there may be a self-selection bias for more active individuals to participate in a study involving questions of this nature.

As demonstrated by the results, the interactions between the determinants of PA are complex. It is not possible, appropriate or effective to assess all possible known psychosocial determinants in one investigation. This presents a limitation to investigations of this nature. The five core predictor variables were chosen for their continued associations with PA in other populations (children, adolescence, and older adults). However, there may be unknown interactions between particular variables that could/could not explain PA behaviors in this population.

\section{Application of Findings}

The logical progression of the present investigation would be to use $\mathrm{EE}, \mathrm{SE}, \mathrm{MO}, \mathrm{SS}$, and $\mathrm{BI}$ as target variables when designing future behavior interventions to improve PA behaviors in young undergraduate college students. Improved PA behaviors resulting from appropriate intervention strategies could lead to development of a standardized approach to programming. Long term, this could have direct application within higher education. Specifically, these strategies if presented in a freshman seminar or orientation course designed to integrate incoming freshman to college life, and may serve as a beneficial method to promote a healthy lifestyle. These types of courses could provide a platform for dissemination of educational and behavioral tools to the students, who would benefit most from such findings. The information gathered from the present investigation might be particularly useful for program developers at the university level because the sample population was selected from undergraduate students currently enrolled in academic programs.

Theoretically based interventions designed to alter PA habits have had little success achieving long-term behavior change in college students [7]. Results of this investigation may be considered when developing new ideas for alternate intervention models. The strength of enjoyment (the strongest predictor of PA in this investigation for both males and females) may suggest that helping students find activities they enjoy is an important factor for improving PA adoption and adherence. A successful intervention in the university setting could introduce a variety of activities that would include sport-like games, outdoor recreation, to structured fitness activities, with the goal of finding new enjoyable activities students might not have previously experienced. Some individuals may prefer group or team-like activities while others may prefer individual activities. Promoting social interaction such as scheduled group bike rides or walks on campus, ties in the concept of social support. Additionally, exercising with others has been shown to add accountability and adherence to a PA program [35].

\section{Future Research}

There are several recommendations for future research when considering the results of this investigation. The present investigation targeted first and second year college students because evidence suggests students are most affected by social and environmental aspects of university life during this time. In a study of Spanish University students where physically active females were older than inactive females [36], it was felt that older students might have more time to adjust to the university experience. This would allow for development of time management skills, and thus, additional free time for PA [36]. Future research should investigate differences between psychosocial determinates of PA in students throughout all years of the undergraduate experience. A longitudinal tracking of PA and assessment of psychosocial determinants of PA from the first to last year of college might also be of interest, and assist in the development of age/class specific PA intervention strategies.

Traditional interventions using determinants of PA often focus on PA as a primary outcome to determine the successfulness of an intervention [37]. Baranowski et al. (1998), recommends focusing on interventions that change mediators of PA rather than PA alone [37]. Additionally, PA interventions may be more effective with a better understanding of the consequences interventions have on determinants [37]. Investigating the effect of a classroom based freshmen orientation, mentoring program, or wellness program on determinates of PA in first year college students is warranted.

Deliens et al. (2015), conducted a qualitative investigation involving focus group discussions in university students and identified four levels of determinants including; individual, social environment, physical environment, and macro environment [38]. Due to the additive nature of determinants of PA, these factors should be examined in combination to provide a comprehensive understanding of the determinants of PA. Finally, to confirm results from the present investigation, similar investigations should explore the relation between psychosocial determinants of PA and objectively measured PA. For example, the combination of a wearable activity monitors and a daily PA diary might eliminate the self-report bias associated with PA recalls and provide a cost effective approach for epidemiologic research of this nature.

\section{Conclusion}

The psychosocial variables targeted in this investigation were explored because of their association to PA in other populations, and for their ability to be altered. It is important to note that the identified determinants from this investigation are but a few of the complex psychosocial, environmental, and demographic determinants of PA behavior. The above-mentioned determinants continue to be important factors in explaining PA in young adult college students. This investigation has identified gender specific trends in determinants of PA for the young adult college population. This is an important step to explaining PA behaviors in a college-age population that is at risk for sedentary behaviors.

Conflict of Interest Disclosure: The authors have no conflicting interest in this study.

\section{References}

1. Booth FW, Roberts CK, Laye MJ (2012) Lack of exercise is a major cause of chronic diseases. Comprehens Physiol 2: 11431211. 
2. Crump C, Sundquist J, Winkleby MA, Sundquist K (2017) Interactive effects of obesity and physical fitness on risk of ischemic heart disease. Int J Obes (Lond) 41: 255-261.

3. Arts J, Fernandez ML, Lofgren IE (2014) Coronary heart disease risk factors in college students. Adv Nutr 5: 177-187.

4. Irwin JD (2004) Prevalence of university students' sufficient physical activity: a systematic review. Percept Mot Skills 98: 927-943.

5. Morrell JS, Lofgren IE, Burke JD, Reilly RA (2012) Metabolic syndrome, obesity, and related risk factors among college men and women. J Am Coll Health 60: 82-89.

6. Keating XD, Guan J, Pinero JC, Bridges DM (2005). A metaanalysis of college students' physical activity behaviors. J Am Coll Health 54: 116-125.

7. Plotnikoff RC, Costigan SA, Williams RL, Hutchesson MJ, Kennedy SG, et al. (2015) Effectiveness of interventions targeting physical activity, nutrition and healthy weight for university and college students: a systematic review and metaanalysis. Int J Behav Nutri Phy Act 12: 45.

8. Uijtdewilligen L, Nauta J, Singh AS, Van Mechelen W, Twisk JWR, et al. (2011) Determinants of physical activity and sedentary behaviour in young people: a review and quality synthesis of prospective studies. British J Sports Med 45: 896905.

9. Dohle S, Wansink B (2013) Fit in 50 years: participation in high school sports best predicts one's physical activity after age 70 . BMC Public Health. 3: 1100.

10. Telama R, Yang X, Viikari J, Valimaki I, Wanne O, Raitakari O (2005) Physical activity from childhood to adulthood a 21-year tracking study. Am J Prev Med. 28: 267-273.

11. Hirvensalo M, Lintunen T (2011) Life-course perspective for physical activity and sports participation. European Review of Aging and Physical Activity 8: 76.

12. Kwan MY, Cairney J, Faulkner GE, Pullenayegum EE (2012) Physical activity and other health-risk behaviors during the transition into early adulthood: a longitudinal cohort study. Am J Prev Med 42: 14-20.

13. Pullman AW, Masters RC, Zalot LC, Carde LE, Saraiva MM, et al. (2009) Effect of the transition from high school to university on anthropometric and lifestyle variables in males. Appl Physiol Nutr Metab 34: 162-71.

14. Centers for Disease Control and Prevention (2015) National Center for Chronic Disease Prevention and Health Promotion Division of Population Health. BRFSS Prevalence \& Trends Data.

15. Bandura A (1986) Social foundations of thought and action: a social cognitive theory. Englewood Cliffs (NJ).

16. Deci EL, Ryan RM (1985) Intrinsic motivation and selfdetermination in human behavior. New York: Plenum.

17. Prochaska JO, DiClemente C (1983) Stages of processes of selfchange of smoking: toward an integrative model of change. $\mathrm{J}$ Consult Clin Psychol 51: 390-395.

18. Lipschitz JM, Yusufov M, Paiva A, Redding CA, Rossi JS, et al. (2015) Transtheoretical Principles and Processes for Adopting Physical Activity: A Longitudinal 24-Month Comparison of Maintainers, Relapsers, and Nonchangers. J Sport Exe Psychol 37: 592-606.

19. Van Dyck D, Cerin E, Conway TL, De Bourdeaudhuij I, Owen $\mathrm{N}$, et al. (2014) Interacting psychosocial and environmental correlates of leisure-time physical activity: A three-country study. Health Psychology 33: 699-709.
20. De Bourdeaudhuij I, Sallis J (2002) Relative contributions on psychosocial variables to the explanation of physical activity in three population-based adult samples. Preventive Med 34: 279-288.

21. McArthur LH, Raedeke TD (2009) Race and Sex differences in college student physical activity correlates. Am J Health Behav 33: 80-90.

22. Guay F, Vallerand RJ, Blanchard C (2002) On the Assessment of situational intrinsic and extrinsic motivation: the situational motivation scale (SIMS). Motivation and Emotion 24: 3.

23. Kendzierski D, DeCArlo K (1991) Physical Activity Enjoyment Scale: Two validation studies. J Sport Exer Psychol 13: 50-64.

24. Marcus BH, Selby VC, Niaura RS, Rossi JS (1992) Self-efficacy and the stages of exercise behavior change. Research Quarterly for Exercise and Sport 63: 60-66.

25. Sallis JF, Grossman RM, Pinski RB, Patterson TL, Nader PR (1987) The development of scales to measure social support for diet and exercise behavior. Prev Med 16: 825-836.

26. Thompson MA, Gray JJ (1995) Development and validation of a new body image assessment scale. J Person Assessment 64: 258-269.

27. Sallis JF, Haskell W, Wood P (1985) Physical Activity assessment in the Five-City Project. Am J Epidemiol 121: 91-106.

28. Taylor CB, Coffey T, Berra K, Iaffaldano R, Casey K, et al. (1984) Seven-Day activity and self-report compared to a direct measure of physical activity. Am J Epidemiol 120: 818-824.

29. Haskell WL, Lee IM, Pate RR, Powell KE, Blair SN, et al. (2007) Physical activity and public health: updated recommendation for adults from the American College of Sports Medicine and the American Heart Association. Circulation 116: 1081-1093.

30. Blair SN, Haskell WL, Ho P, Paffenbarger RS, Vranizan KM, et al. (1985) Assessment of habitual physical activity by a sevenday recall in a community survey and controlled experiments. Am J Epidemiol 122: 794-804.

31. Salmon J, Owen N, Crawford D, Bauman A, Sallis J (2003) Physical activity and sedentary behavior: A population-based study of barriers, enjoyment and preference. Health Psychol 22: 178-188.

32. Dyrstad SM, Hansen BH, Holme IM, Anderssen SA (2014) Comparison of self-reported versus accelerometer-measured physical activity. Med Sci Sports Exer 46: 99-106.

33. Bauman AE, Reis RS, Sallis JF, Wells JC, Loos R JF, et al. (2012) Correlates of physical activity: why are some people physically active and others not? The Lancet 380: 258-271.

34. Van Dyck D, De Bourdeaudhuij I, Deliens T (2015) Can change in psychosocial factors and residence explain the decrease in physical activity during the transition from high school to college and university? Int. J. Behav. Med 22: 178-186.

35. Rackow P, Scholz U, Hornung R (2014) Promoting Exercise Behaviour and Well-being: the Kind of Received Social Support Makes the Difference. European Health Psychologist 16: 335.

36. Romaguera D, Tauler P, Bennasar M, Pericas J, Moreno C, et al. (2011) Determinants and patterns of physical activity practice among Spanish university students. J Sports Sci 29: 989-997.

37. Baranowski T, Anderson C, Carmack C (1998) Mediating variable framework in physical activity interventions. How are we doing? How might we do better? Am J Prev Med 15:266-297.

38. Deliens T, Beforche B, De Bourdeaudhuij I, Clarys P (2015) Determinants of physical activity and sedentary behavior in university students a qualitative study using focus group discussions. BMC Public Health 15: 201. 